\title{
Antecedents of Perceived Service Quality: Focus on Private Health Facilities in Ghana
}

\author{
Jackson Awuah Brobbey \\ Nobel International Business School, Accra-Ghana
}

Received: December 12, 2021 Accepted: January 13, 2021 Published: January 19, 2022

doi:10.5296/jbls.v13i1.19319 URL: https://doi.org/10.5296/jbls.v13i1.19319

\begin{abstract}
The main purpose of the study is to understand service quality in private healthcare facilities in Ghana. The study sought to find out factors affecting perceived service quality of private health facilities in Ghana. The study made use of a quantitative method which was in the form of an explanatory research design. Further to this, quantitative research was conducted with larger sample of two hundred and fifty (250) patients of private health care facilities. The researcher employed multiple regression analysis to analyze the data. The results of the study revealed that there was a positive and significant relationship between technical knowledge, provider responsiveness, effective leadership and collaboration. Among other important implications, the study recommended that, as a result of the positive and significant relationship established between the supported variables, stakeholders and management invest more into the training of hospital staffs in these critical areas of service delivery. Also, the study presented that, healthcare providers should be able to communicate with other professional in delivering healthcare.
\end{abstract}

Keywords: service quality, patients, healthcare, private healthcare facilities

\section{Introduction}

With the health sector as the foci of the research, it is important to note that, in spite of this rapid growth, there are still major challenges facing the health sector in Ghana in terms of delivering of quality service. The changing customer demands and global competition has increased expectation of quality of services in health care facilities (Irfan \& Ijaz, 2011). Customers of healthcare facilities now look out for quality when selecting a product or a service (Protzman, Mayzell \& Kerpchar, 2018). At the same time healthcare facilities are putting measures in place to provide quality services to meet the needs and wants of customers. Service quality is now viewed as a strategic tool for organizations to gain business success (Irfan \& Ijaz, 2011; Carey et al., 2018).

It is important to note that, there has been the emergence of a number of healthcare facilities 
in Ghana due to the influx of numerous private and public healthcare facilities. The number of healthcare facilities springing up has eased accessibility to healthcare delivery and brought healthcare to the doorstep of the ordinary person. A number of them include municipal hospital, district hospitals and poly clinics and other major private hospitals. Both the private and public health facilities deliver healthcare to the general public. This is in line with the fact that the health status of the people in the country determines how productive the economy will be.

Despite the contribution of the healthcare facilities, there has been major issue concerning the quality of service provided at these establishments (e.g. Andaleeb, 2001; Mathauer \& Imhoff, 2006; Matsea, Ryke \& Weyers, 2018). Poor quality of service in some healthcare institutions in the country has been a concern expressed in recent times and this has been the concern of Shafiq, Naeem, Munawar and Fatima (2017) who said, current service quality levels in the healthcare sector is worrying. Patients are not receiving the required help and making them look elsewhere for alternative. This has greatly affected the credibility of the health sector as there has been a lot of complaints about the quality of service delivered (Yousaf, Grunfeld \& Hunter, 2015).

Further to this, affordability of health care in Ghana is seen a major problem. This is because, if ordinary people cannot afford to pay for health services, then complaining about quality is an issue for the few ones who can afford. Affordability of health care is a serious problem in Ghana, perhaps that is why most customers are reticent about service quality. In Ghana, a report released by the Ghana Health Service (2009, p.19), it opines that " $65 \%$ to $95 \%$ of unhappy but non-complaining customers will never patronize the services of health institutions with poor service quality". Most customers complain to friends and family but not to the appropriate healthcare authorities and this report suggest that people are prepared to utilize service providers who give out quality healthcare delivery and service. There have been complaints about unresponsive and disrespectful attitude of staffs and not giving customers' recognition and attention (Ojwang, Ogutu \& Matu, 2010). Mosadeghrad (2014) in his qualitative study identified some determinants of service quality and patient satisfaction which have not been empirically tested. This study will therefore examine how organizational factors, patient related factors, provider related factors and the environmental factors impacts on the perceived service quality using private healthcare facilities in Ghana.

\section{Review of Related Literature}

\subsection{Service Quality in Healthcare Sector}

Garcia (2019) noted that the healthcare sector is one of the most important and sophisticated disciplines in society as people's lives are involved. In view of this, the issue of quality in the healthcare services becomes indispensable. A number of scholars have identified and measured healthcare service quality attributes and patient satisfaction. Owusu-Frimpong, Nwankwo and Dason (2010) examined the accessibility of public and private healthcare facilities in London with regards to patients' satisfaction and concluded that patrons of private healthcare centres were more satisfied than those who patronized public facilities. They conceded that patrons of public facilities were saddled with significant challenges in 
healthcare accessibility. Perception of patient's experience of particular healthcare institutions also affect profitability and image of the hospital (Donabedian, 1980) and it also considerably affects the extent to which patient propagate their experience (Andaleeb, 2001). Pakdil and Harwood (2005), asserts that these heightened patient's expectations has forced healthcare facilities to prioritize key determinants of customer satisfaction and focus their attention on them. This shows that healthcare institutions treat service quality and patient satisfaction issues with all the attention it deserves and factor it in their strategic goals.

\subsection{Theory}

The disconfirmation theory of service quality is one of the theories to explain service quality and customer satisfaction. According to the disconfirmation theory, customer satisfaction is measured or determined by the level of discrepancies that exist between the customer's expectation of a service to be provided and the perceived performance. (Khalifu \& Liu, 2003). The beliefs, perception and desires of a customer about a product or a service can be said to be the customer expectation (Mckinney et al; 2002). In a research conducted by Zeithaml and Berry (1988), they asserted that the expectation of a customer about a service or product on offer is likely to happen when making exchange or a transaction. A customer's judgement about a firm's superiority is the perceived quality of a customer. Disconfirmation actually refers to what a customer expects to gain from a service and what the customer actually receives from the provision of that service (Oliver, 1996). We can therefore define disconfirmation as the subjective judgement of a customer which results from the comparison between his expectations and perception of performance (Spreng \& Mackoy, 1996). The disconfirmation theory states that "satisfaction is affected by the intensity (or size) and direction (positive or negative) of the gap (disconfirmation) between expectations and perceived performance" (Amanfi, 2012).

When the consumers become more familiar with the service they tend to form more realistic expectations about it, which leads to a lower disconfirmation gap. However, the smaller gap by itself does not indicate high level of quality or satisfaction. Expectations towards a service, which requires high customer involvement and where the customer is involved in the co-creation of the service, may be influenced by customer`s self-esteem and his/her own perception about how capable they are. The disconfirmation model thus tries to assess whether there are differences in the expectations of services provided and the perceived service quality of the patient. When organisational factors, patient related factors, provider related factors and environmental related factors from the perspective of the hospital providers improves, this confirms the expectations of patients and in turn lead to positive perception about service quality of the healthcare facilities. The disconfirmation theory posits that, when caregivers are able to provider services which meets the needs of patients, then it meets their expectation leading to positive perception of quality. To buttress the above, when there are higher technical skills from caregivers, when providers are responsive and empathic to patients, collaborates effectively with patients even with severe illness and have better facilities, then the expectations of the patients about the provider is met and this in turn leads to positive perception of the patients about the hospital facility. 


\subsection{Conceptual Framework}

\section{Organisational Factors}

- Technical knowledge

- Provider responsiveness

- Provider facility/ amenity

\section{Patient Related Factors}

- Severity of patient illness

- Patient cooperation

- Provider empathy

\section{Provider Related Factors}

- Provider motivation

- Provider competency

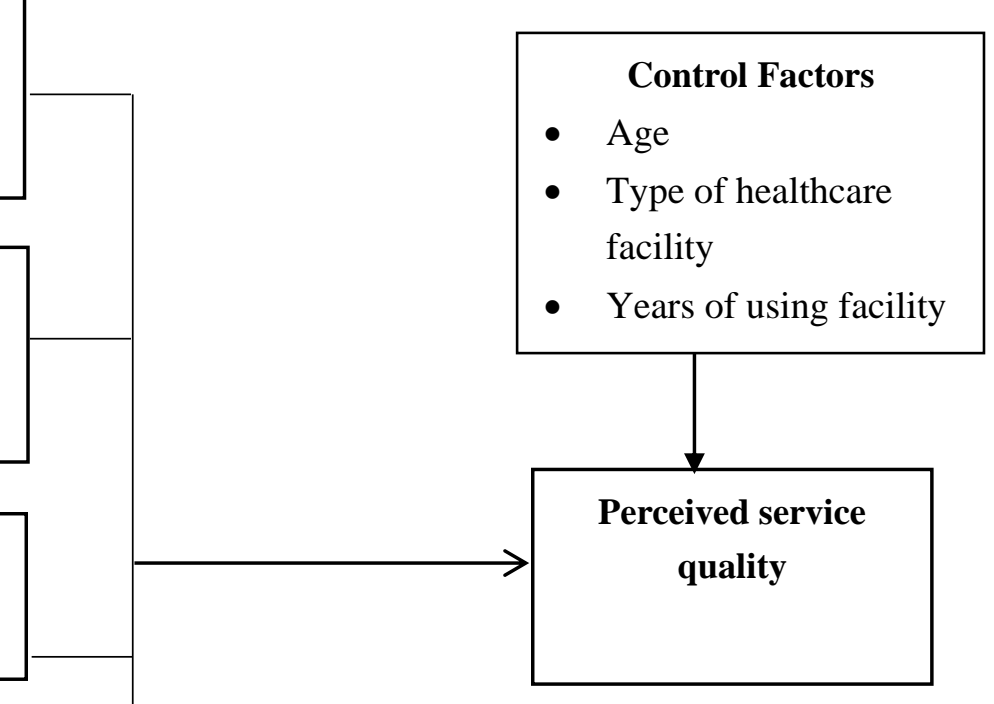

\section{Environmental Factors}

- Cost of healthcare

- Effective leadership

- Collaboration of healthcare providers

Figure 1. Conceptual model

\subsection{Development and Presentation of Hypotheses}

Technical knowledge -This refers to the ability of care givers which includes doctors, physicians and other medical staff to be able to diagnose patients' sickness and other ailment and be able to treat them with the appropriate medication and methods (Donabedian, 1986). Gronroos (1983) was also of the view that, technical quality relates to the delivery and extent of their technical quality. He goes on to say that; patients' perceptions of the service quality depend on the service they receive from caregivers. Other researchers (e.g. Maddern, Maull, Smart \& Baker, 2007) were also of the view that the technical knowledge of the healthcare facilities translates into higher patients' perceived quality. In the hospital setting, when the care givers are experienced and knowledgeable in their field of expertise, patient feel safe and confident in dealing with the personnel involved. Eiriz and Figueiredo (2005) were of the view that lack of technical knowledge on the part of providers could impact on the financial performance of the facility because patients will not make use of the service provided by such healthcare givers because their expectations have not been met. It is important to state that, when patients do not trust the technical knowledge of healthcare providers, they will not be willing to receive healthcare service. The disconfirmation theory stresses that, when patients trust the technical knowledge of their service providers, then it leads to higher perception of service quality leading to their overall satisfaction. Based on the above review, the researcher hypothesizes that: 
Hypothesis 1: There is a positive relationship between technical knowledge of healthcare providers and patient perceived service quality

Provider responsiveness - This refers to the ability of the healthcare provider to be responsive to the needs of patients, have a friendly relationship with the patients and pay attention to details of assertions of the patient regarding his/her condition (Donabedian, 1986). There have been inconclusive results concerning how interpersonal component of healthcare impact on patient satisfaction (Tucker \& Adams, 2001). Murray and Frenk (2000) in their study identified respect for patients and patient orientation as important dimensions of provider responsiveness. Using the disconfirmation theory, they show that when healthcare givers become sensitive to the plight of the patients, there is positive perception of the patients towards caregivers. Provider responsiveness could impact on perceived quality of the patient when there is respect for their basic human right and respect for the patients' autonomy. A higher positive perception of hospital quality is achieved when doctors put themselves in the shoes of the patients, feel their patients and be in the position to offer prompt services to them (Charles, Gafni \& Whelan, 1997).

Because co-creation is a characteristic of service, the involvement of hospital providers is imperative for higher perceive quality. Co-creation relates to the effective collaboration between service providers and patients and once care givers relates well to patients, then there is higher perceive quality. For example, Taylor and Cronin (1994) was of the view that perceptions of patients concerning how hospital staffs relates to them is an important indicator of perceived quality as their expectations are met. They recommend that for service quality to be high, there is the need to develop quality measures such as respect and expert judgement. The researcher hypothesizes that:

\section{Hypothesis 2: There is a positive relationship between provider responsiveness of healthcare and patient perceived service quality}

Provider facilities -This refers to the availability of infrastructure and materials in the facility; and also, the appeal and comfort of these facilities (Donabedian, 1986). It could also be used to refer to the availability of hospital facilities and equipment which are standard and are able to provide excellent service for patients. High quality input leads to high quality output. Mosadeghrad (2014, p.84) assert that "resource shortage also increases employee's job stress which consequently affects the quality of their work..... managers and policy makers recognized financial resources as the most important factors affecting the quality of healthcare". When there is availability of resources and facilities, patients are exposed to world class services and new technologies. Obsolete equipment will not be able to serve the current needs of clients and therefore the service quality will be low. When there is good infrastructure like pharmacies, wards, dressing rooms, laundry, mortuaries, maternity wards, patients feel secured to patronize the services of the facilities.

Patients perceived quality will be achieved when their expectations are met in relation to the available facilities in the hospital. When the available facilities of the hospital meet the expectation of the patient, then there is continual utilization of the service (Jirsch, 1993). Based on the above review, the researcher hypothesizes that: 
Hypothesis 3: There is a positive relationship between the available provider facilities and patient perceived service quality

Severity of patient illness: This refers to the complexities of the illness of patients (Jun, Peterson \& Zsidisin, 1998). The severity of Illness of patient also affects the quality of healthcare provided by hospitals. The type of illness may have impact on the health personnel who are working in the hospital and it likely to affect the quality of service delivered (Mosadeghrad, 2014). According to researchers (Jackson, Chamberlin \&Kroenke 2001; Chang et al. 2006; Keenan et al. 2005), the complexities of the diseases of patients affected their perceived quality. Especially for low income earners, when they receive treatment from doctors regarding certain diseases they consider to be complex, they are more satisfied with the services (Salisbury, Wallace \& Montgomery, 2010) because their expectations are met. Patients with more severe illness have higher perceived quality once they receive medical care, unlike patients with less severe/ complex illness. Similarly, Werner and Chang (2008) supported the assertion that there is higher perceived quality for patient with higher illness complexity. Other researchers (e.g. Peterson et al, 2009) however found no relationship between severity of illness and patient perceived service quality. There have been inconclusive results on this relationship, but the assertion of Fan et al (2008) proves that, service could further be strengthened, when providers give the necessary education relating to other self-management practices, like taking medicines on time and the right volume to take. Based on the above review, the researcher hypothesizes that:

\section{Hypothesis 4: There is a positive relationship between the severity of patient illness and patient perceived service quality}

Patient cooperation: This study makes use of the definition of adherence as synonymous to cooperation as argued by Arbuthnott and Sharpe (2009). Patient cooperation is therefore "the extent to which a person's behavior coincides (in terms of taking medications, following diets, or executing lifestyle changes) with medical or health advice" (Haynes, Taylor, Snow \& Sackett (1979, p.1-2). In general, patient cooperation refers to how patients heed to the medical advice of caregivers. In an interview conducted with a respondent, Mosadeghrad (2014) reveal that, "if the personnel do their job well, but the patient does not follow medical orders, the objectives would not be achieved". The involvement and cooperation of both the patient and the personnel in charge is very keen in the provision of quality healthcare. Bleich, Özaltin and Murray (2009) assert that when there is high level of cooperation between a patient and a service provider, then it implies that there is trust which invariably leads to quality of service. From co-creation, as a service characteristic, Lusch et al (2007) assert that, when there is effective cooperation between caregivers and their patients then there is positive perceive quality. Cooperation leads to better and quality healthcare. Further to the above, when patients cooperate, then it means they are ready to receive medical assistance and this also implies that, they want their expectations to be met. A patient who does not cooperate with caregivers is not willing to receive medical care and therefore will not be satisfied with the service given, even in the case where there is optimal service delivery. Based on the above review, the researcher hypothesizes that: 
Hypothesis 5: There is a positive relationship between patient cooperation and patient perceived service quality

Provider empathy: Provider empathy refers to the perception of the patient towards how caregivers understand their feelings. Provider empathy is about the perception of patients on how the caregivers understand their mental state. Kim (2000) assessed the extent to which the provider empathy leads to higher perceived quality. He proposed that providers who are empathic to their patient will cause their patient to be more satisfied by doing so, patients have positive perceptions about the service received. Other researchers (e.g. DiMatteo, Taranta, Friedman, \& Prince, 1980 and Hojat et al., 2002) hold similar view that patient satisfaction is normally attributed to the level of empathy between the provider and the patient. When there is empathy from the service provider, patients appreciate the role of the caregivers. This is because patients' feel caregivers understands them and their situation. The personality and character of healthcare providers affect the quality of health service.

In line with co-creation as an effective service characteristic, the researcher is of the view that, because of the involvement of caregivers or healthcare providers and patients in the service process, providers should show empathy in order for patients to be comfortable with the service they received. As caregivers, there is the need-to-know what patients go through and once patients feel their caregivers are empathetic to them, it speeds us their recovery because they feel others have gone through similar ordeal. Weatherall (1995) supports this assertion, by stating that, there is the need to revise the pattern of medical education to incorporate basic skills like humanness, kindness and empathy. This makes patients feel satisfied with the services received from caregivers. Thus, we hypothesise that;

\section{Hypothesis 6: There is a positive relationship between empathy of the service provider and patient perceived service quality}

Provider motivation: Provider motivation refers to the extent to which caregivers are satisfied with their allowances and benefits received periodically and also their inert passion to help others (Leff \& Warner, 2006). When health personnel are motivated and they are satisfied, they deliver high quality service to the clients (Mittal \& Lassar, 1998). In his research, Mosadeghrad (2014) identified nine main determinants of motivation and satisfaction to include job identity, job security, recognition, co-workers, organizational policies, managerial leadership, working environment and chances of promotion. When healthcare workers are motivated, they provide optimal service to their patients and this implies that patient will be satisfied with the quality of healthcare service they are receiving from providers.

Also, when working condition in hospital facilities are not favorable, staffs do not give out their best and this will reduce the quality of service they give to their patient (Bowling, 2014). This will translate to poor service quality which will reduce the level of patient satisfaction. We are therefore of the view that, high motivation will translate to higher service quality which will in turn translate higher patient satisfaction because of the fact that healthcare providers are providing efficient services. When caregivers are motivated both intrinsically and extrinsically, they give out their best in the delivery of service to patients. When optimal services if rendered to patients as a results of the satisfaction of the caregivers, then there is 
higher perceived service quality from the perspective of the patient. Based on the above review, the researcher hypothesizes that:

\section{Hypothesis 7: There is a positive relationship between provider motivation and patient perceived service quality}

Provider competency: This refers to the technical skills and knowledge of practitioners in giving required services to patients (Coyne et al., 2016). Provider competency has to do with the skills, knowledge and expertise of the caregiver and the effectiveness of his/ her diagnosis and treatment. Mosadeghrad (2014) was of the view that there is the need for healthcare providers to enhance their commitment, expertise, knowledge and be able to examine patient properly in order to make patients satisfied. Kane (1992) also asserted that, professional competence leads to higher service quality which in turn leads to higher customer satisfaction. This is because with higher professional competence, caregivers give out their optimal best in the treatment of patients, and their patients develop a higher perception of the quality of service provided them. When providers do not have the required competence, they are not in the position to deliver expected service to patients, and once the expectations of patients are not met, they perceive a low service quality which makes them unsatisfied.

There is therefore the need for caregivers to possess the required competencies, traits, skills and knowledge in order to deliver optimal level of service to patients. Jonsdottir, Litchfield and Pharris (2004) assert that when there are higher competencies like permanent learning, communication and critical thinking, it equips the providers to provide quality services which leads to patient satisfaction and perceived service quality because the expectations of patients are met. The mental outlook of caregivers all play important role in ensuring competence. Without adequate competence, providers cannot offer superior service to their client. Based on the above review, the researcher hypothesizes that:

\section{Hypothesis 8: There is a positive relationship between provider competency and patient perceived service quality}

Cost of healthcare: This refers to the level of affordability of services patients receive from healthcare facilities. The availability of health referral systems is important in the provision of quality healthcare, but affordability of the health facility is an important determinant of perceived quality of service of healthcare. Fees between different healthcare systems should not deviate from the average in order for all client to be able to access healthcare (Mosadeghrad, 2014). The cost of assessing healthcare is an important predictor of quality especially to low income earners. When the hospital also accepts health insurance cards, it makes them easy to assess healthcare without any worry. When there are interrelations in the health system, there is higher patient satisfaction. When the cost of providing healthcare is high, patient might resort to some other means of taking care of themselves, thereby having a negative perception about the service provided. When the cost of receiving healthcare is affordable, patients are able to visit hospital facilities because they are in the position to pay for the service. Based on the above review, the researcher hypothesizes that:

Hypothesis 9: There is a negative relationship between the cost of healthcare and patient 
perceived service quality

Effective leadership: This refers to existence of a management body which seeks to achieve higher organisational performance by enhancing the capabilities of all staffs to improve medical outcomes and quality of care (Ghiasipour, Mosadeghrad, Arab \& Jaafaripooyan, 2017). There have been extensive studies which have revealed that, most problems faced by healthcare facilities are due to bad leadership. According to Mosadeghrad and Abbasi (2018), poor leadership reduces effectiveness, efficiency and increases cost and ultimately resulting in dissatisfaction among staffs and lowering patients' satisfaction, because caregivers do not give their best in the delivery of service. When there is effective leadership, it reduces conflict among staffs and their departments and this helps in advancing the performance of the facility (Benzer et al., 2012). The researcher believes that with effective leadership in healthcare facilities, caregivers are appointed through the right channel. Based on the above review, the researcher hypothesizes that:

\section{Hypothesis 10: There is a positive relationship between effective leadership and patient perceived service quality}

Collaboration of healthcare providers: This refers to the extent of information and knowledge sharing between healthcare professionals in different healthcare facilities. According to Mosadeghrad (2014), “practitioners' ability to effectively communicate and collaborate with other professionals or institutions was also considered essential to the delivery of high quality healthcare services". When there is collaboration, experiences are shared between health professional and with this caregiver provide standard forms of treatment based on best practices elsewhere. Similarly, when there is good communication between caregivers of different facilities, they are able to share information and knowledge on particular illness, and with this, they are in the position to better provide the needed medication and treatment of their patients. It is important for caregivers to share information, knowledge and ideas between themselves and by doing so, new methods of treatment and best practices could be adopted. This is likely to lead to higher perceive service quality because patients are assured of better services in their hospital or the referral agency. There is also higher perceived quality because there are various alternatives for the patient to utilize. Based on the above review, the researcher hypothesizes that:

\section{Hypothesis 11: There is a positive relationship between collaboration of healthcare providers and patient perceived service quality}

\section{Methodology}

\subsection{Population, Sampling and Sample Size}

The researcher used stakeholders of the healthcare sector of Ghana who are in the service industry as population for the study. The population for the study include management of private healthcare facilities in Ghana and clients/patients who make use of these facilities. The researcher made use of the purposive sampling approach to gather respondents for the study. Purposive sampling is type of non-random method which allows the research select 
participants with relevant and rich experience on the phenomena of study (Merriam, 1998). The use of this sampling strategy is used when the respondents possess vital and rich information which will contribute immensely to the achievement of the objectives of the study. Getting the total number of respondents who accessed healthcare in Ghana was not readily available with Ghana Health Service and so the researcher used the suggestion by Hair, Black, Babin and Anderson (2010) that, in the case where the total number of the population is unknown, to get the adequate sample frame, the respondents should be 5- 10 times the number of items used in the questionnaire. The total number of items used in measuring the dependent and independent variables in the questionnaire were 99 and therefore, the sample frame was between 495 and 990

\subsection{Data Analysis Procedure}

The main computer-based software which aided data analysis was the Statistical Package for Social Sciences (SPSS). These were adopted in running the data gathered from the field. Some aspects of the data collected from institutions, individuals, and other stakeholders were analyzed quantitatively. Multiple Regression Analysis was used to analyze the data to make inferences and based on that, conclusions were drawn and implications of the results given.

\subsection{Measurement and Validation}

Issues relating to validity and reliability of the study findings and recommendations were of high interest while securing and ensuring the acceptability of the results or findings of this study. Whereas validity connotes the integrity of the final conclusions drawn from a research activity, reliability is more concerned about the consistency of measurements in the research (Bryman, 2004). Research validity, therefore, denotes the various inferences and deductions arrived at about the quality of diverse fragments of the research methodology. The quality of the approaches used in the various aspects of the research determines how near the final results are close to a valid conclusion. The validity and reliability of the findings ensure that at the end of the research, the results could be applicable in subsequent research works. To ensure validity of the constructs used for the study, convergent validity and discriminant validity procedure was used. The Cronbach alphas of all the constructs were also assessed.

\section{Results and Findings}

This chapter presents the quantitative results and findings of the study. The study focused on identifying the extent to which organizational, customer related, provider-related and environmental factors of the healthcare facilities in Ghana affect service quality. The chapter also highlights the decisions made with respect to the hypothesis developed for the study.

\subsection{Exploratory Factor Analysis}

A principal component analysis (PCA) was conducted on 55 items using varimax rotation. The Kaiser-Meyer-Olkin measure verified the sampling adequacy for the analysis, KMO $=.855$ ('superb' according to Field, 2009), and all KMO values for individual items were $>.50$, which is well above the acceptable limit of 0.5 (Field, 2009). Bartlett's test of sphericity $\chi^{2}(2016)=15976.866, p<.001$, indicated that correlations between items were 
sufficiently large for PCA. An initial analysis was run to obtain eigenvalues for each component in the data. Factors with cross loadings were deleted to ensure unidimensionality of the factors. The final analysis showed that 12 components had eigenvalues over Kaiser's criterion of 1 and in combination explained $58.855 \%$ of the variance. Table 4 shows the factor loadings after rotation. A maximum likelihood analysis (MLA) was conducted on the 22 items of service quality with promax rotation because of evidence in literature that the variables in the study correlate with each other. The Kaiser-Meyer-Olkin measure verified the sampling adequacy for the analysis, $\mathrm{KMO}=.737$ ('superb' according to Field, 2009), and all KMO values for individual items were $>.50$, which is well above the acceptable limit of 0.5 (Field, 2009). Bartlett's test of sphericity $\chi^{2}(136)=2300.544, p<.001$, indicated that correlations between items were sufficiently large for MLA. An initial analysis was run to obtain eigenvalues for each component in the data. Factors with cross loadings were deleted to ensure unidimensionality of the factors. The resultant analysis showed that four components had eigenvalues over Kaiser's criterion of 1 and in combination explained $47.426 \%$ of the variance. Table 4 shows the factor loadings after rotation. The items that cluster on the same components suggest that component 1 represents reliability, component 2 as tangibility, component 3 as empathy and component 4 as responsiveness

Table 1. Principal component analysis of items

\begin{tabular}{lcccccccccccc}
\hline & $\mathbf{1}$ & $\mathbf{2}$ & $\mathbf{3}$ & $\mathbf{4}$ & $\mathbf{5}$ & $\mathbf{6}$ & $\mathbf{7}$ & $\mathbf{8}$ & $\mathbf{9}$ & $\mathbf{1 0}$ & $\mathbf{1 1}$ & $\mathbf{1 2}$ \\
\hline Amenity2 & .264 & .802 & .137 & -.058 & .177 & .032 & .010 & .364 & -.175 & .119 & .054 & -.025 \\
Amenity3 & .178 & .748 & .105 & .219 & .060 & -.017 & .087 & .063 & -.053 & .207 & .023 & .074 \\
Amenity5 & .243 & .586 & -.047 & .441 & .011 & .031 & .036 & .141 & .034 & .073 & .016 & -.165 \\
Inter6 & .712 & .072 & .310 & .274 & .054 & -.006 & .106 & .518 & -.003 & .166 & .043 & .107 \\
Inter7 & .679 & .035 & .113 & .017 & .086 & -.060 & .007 & .024 & -.102 & .142 & .029 & .066 \\
Inter8 & .795 & .069 & -.067 & .009 & .037 & .087 & -.051 & .007 & .001 & -.019 & -.022 & -.198 \\
Inter9 & .795 & .152 & -.077 & .038 & -.009 & .068 & -.067 & -.040 & .024 & .107 & .035 & -.022 \\
Inter10 & .776 & .053 & -.097 & .138 & -.084 & -.008 & .002 & -.019 & .026 & -.018 & .019 & -.108 \\
Inter11 & .747 & .009 & .015 & .130 & -.080 & -.410 & -.073 & .038 & .013 & -.057 & -.009 & -.011 \\
Tech12 & .289 & -.128 & .166 & .773 & -.082 & -.111 & -.049 & .136 & .022 & -.053 & -.028 & .023 \\
Tech13 & -.036 & -.034 & .090 & .699 & .045 & -.175 & -.008 & .025 & -.046 & .097 & -.120 & -.114 \\
Tech14 & -.127 & -.064 & .111 & .503 & .087 & -.064 & .066 & .054 & -.120 & .280 & .070 & .062 \\
Tech15 & -.106 & -.032 & -.005 & .617 & .005 & -.002 & .071 & .132 & -.002 & .251 & .027 & -.150 \\
TypeIllness1 & -.171 & .095 & .345 & .273 & .618 & -.044 & .095 & .400 & -.077 & .321 & .066 & .029 \\
TypeIllness2 & .067 & .099 & .030 & .148 & .705 & .027 & .000 & .171 & .040 & .706 & .101 & -.040 \\
TypeIllnness3 & -.051 & .082 & -.016 & -.039 & .668 & -.001 & -.075 & .039 & -.003 & .243 & .171 & -.093 \\
TypeIllnness4 & -.053 & .153 & .062 & .053 & -.675 & -.133 & -.036 & -.125 & -.064 & .211 & .100 & .084 \\
PatCop3 & -.142 & .057 & .007 & .229 & .032 & .135 & -.121 & -.063 & .718 & .107 & .097 & .106 \\
PatCop4 & -.110 & -.131 & .107 & .638 & -.017 & -.112 & -.042 & -.004 & .627 & .056 & -.055 & .091 \\
Motivation1 & -.121 & -.044 & -.078 & .249 & .031 & -.055 & -.013 & .022 & -.035 & .026 & .683 & -.115 \\
Motivation2 & -.050 & -.101 & .242 & .020 & -.006 & -.101 & -.033 & .259 & .009 & .110 & .556 & .086 \\
Motivation3 & -.132 & .014 & .040 & .144 & -.060 & -.029 & -.011 & .132 & -.035 & .703 & .689 & -.026
\end{tabular}




\begin{tabular}{lcccccccccccc} 
Motivation4 & -.006 & .007 & -.009 & .056 & .087 & .055 & .004 & .064 & .107 & -.121 & .594 & -.011 \\
Motivation5 & .002 & .029 & -.204 & .078 & .068 & .126 & .076 & .081 & .059 & .109 & .568 & -.141 \\
ProCompe2 & -.031 & -.030 & .673 & .134 & -.008 & -.068 & -.047 & -.056 & -.049 & -.078 & .047 & .751 \\
ProCompe4 & .040 & .119 & .191 & .013 & -.410 & .072 & -.046 & .310 & -.016 & -.046 & -.104 & .812 \\
ProCompe5 & .005 & .057 & .622 & .096 & -.111 & -.019 & .068 & -.096 & .007 & .160 & .018 & .757 \\
\hline
\end{tabular}

Table 1 cont'd. Principal component analysis of items

\begin{tabular}{|c|c|c|c|c|c|c|c|c|c|c|c|c|}
\hline & 1 & 2 & 3 & 4 & 5 & 6 & 7 & 8 & 9 & 10 & 11 & 12 \\
\hline ProSocio1 & .156 & -.012 & .794 & .053 & -.072 & -.410 & -.057 & .010 & .042 & -.038 & -.054 & .195 \\
\hline ProSocio2 & .150 & -.106 & .816 & .006 & -.030 & -.111 & .044 & .087 & .051 & .011 & -.023 & .116 \\
\hline ProSocio3 & .270 & -.067 & .820 & -.006 & .001 & -.175 & .026 & .036 & -.021 & -.014 & .064 & .046 \\
\hline ProSocio4 & .176 & -.091 & .838 & -.043 & .030 & -.064 & .016 & .106 & .036 & .094 & .069 & -.073 \\
\hline ProSocio5 & .113 & -.041 & .768 & -.017 & -.026 & -.002 & .076 & .007 & .011 & -.009 & .108 & -.042 \\
\hline Healthcare1 & .197 & -.067 & .254 & .852 & .074 & -.044 & .083 & -.051 & .035 & .100 & .105 & -.107 \\
\hline Healthcare2 & .220 & -.134 & .009 & .816 & -.095 & .027 & -.057 & -.067 & .106 & .019 & .768 & -.037 \\
\hline Healthcare4 & .009 & -.104 & -.037 & .540 & -.002 & -.001 & .127 & .002 & .082 & -.079 & .312 & -.012 \\
\hline Healthcare5 & .108 & -.126 & .080 & .781 & .069 & -.133 & .119 & -.073 & .160 & .115 & .234 & -.045 \\
\hline Healthcare6 & .109 & .046 & .131 & .819 & .015 & .135 & .007 & -.049 & -.052 & -.069 & .134 & .101 \\
\hline Resource1 & .184 & -.032 & .091 & .019 & -.005 & .759 & .051 & -.008 & .043 & -.028 & .020 & -.039 \\
\hline Resource2 & .249 & .031 & .024 & -.077 & -.032 & .864 & -.050 & .066 & -.035 & -.009 & .085 & .121 \\
\hline Resource3 & .225 & .017 & .061 & -.086 & .026 & .773 & .012 & .071 & .021 & .118 & .055 & .008 \\
\hline Resouce4 & .081 & .009 & .103 & .035 & -.078 & .769 & -.035 & .095 & .072 & .047 & .719 & .032 \\
\hline Resource5 & .276 & .044 & .228 & .021 & .103 & .721 & -.004 & .000 & -.024 & .080 & .023 & .102 \\
\hline Lead1 & .199 & .006 & .812 & .076 & -.002 & -.009 & .657 & -.075 & -.036 & -.078 & .128 & -.077 \\
\hline Lead2 & .169 & .056 & .358 & .093 & .014 & .043 & .608 & -.036 & .067 & -.042 & -.117 & .164 \\
\hline Lead3 & .179 & -.090 & .317 & .012 & -.017 & .040 & .679 & -.121 & .027 & .107 & .026 & .061 \\
\hline Collabo1 & .533 & .030 & .487 & -.060 & -.132 & .011 & .158 & -.042 & -.027 & .740 & .239 & .024 \\
\hline Collabo2 & .503 & -.069 & .033 & -.021 & -.254 & .085 & -.226 & -.013 & -.077 & .547 & -.060 & .471 \\
\hline Collabo4 & .087 & -.009 & .066 & -.035 & .079 & .140 & -.021 & -.033 & .116 & .519 & -.014 & .689 \\
\hline Collabo5 & .009 & -.117 & -.059 & .002 & .025 & .050 & .053 & -.011 & .245 & .524 & .030 & .575 \\
\hline GenSatis1 & -.050 & -.004 & .094 & -.007 & .114 & .051 & .005 & .823 & .042 & -.072 & .229 & .135 \\
\hline GenSatis2 & .077 & .062 & .192 & .073 & -.004 & .005 & -.019 & .803 & .051 & -.055 & -.013 & .089 \\
\hline GenSatis3 & .158 & -.014 & .043 & .031 & .198 & .072 & -.034 & .829 & -.021 & .158 & .004 & .117 \\
\hline GenSatis4 & .156 & -.110 & .078 & -.019 & -.030 & -.049 & -.064 & .650 & .036 & .144 & -.012 & -.005 \\
\hline
\end{tabular}


Table 2. Maximum Likelihood Analysis of items

\begin{tabular}{lrrrrr}
\hline & \multicolumn{5}{c}{ Factor } \\
& \multicolumn{1}{c}{. } & 2 & 3 & \multicolumn{1}{l}{4} \\
\hline Tangibility2 & .047 & .699 & .040 & -.026 \\
Tangibility3 & -.002 & .791 & -.011 & -.039 \\
Tangibility4 & -.093 & .727 & .007 & .015 \\
SQEmpathy1 & -.058 & -.134 & .632 & .033 \\
SQEmpahty2 & .042 & .022 & .817 & .055 \\
SQEmpathy3 & -.006 & .065 & .837 & -.026 \\
SQEmpathy5 & .002 & .418 & -.054 & .029 \\
SQEmpathy6 & .036 & .496 & -.003 & .024 \\
SQEmpathy7 & .022 & .466 & -.003 & .031 \\
Relia2 & .550 & .008 & -.050 & .068 \\
Relia3 & .901 & -.012 & .032 & -.061 \\
Relia4 & .746 & -.016 & .013 & -.009 \\
Relia5 & .824 & .027 & -.017 & -.051 \\
Respon2 & .350 & .004 & .011 & .705 \\
Respon3 & .024 & .006 & -.046 & .848 \\
Respon4 & -.029 & .038 & .009 & .675 \\
Respon5 & -.021 & -.021 & .100 & .392 \\
Eigen values & & & & \\
Percentage of variance explained & & & & \\
Cumulative percentage of variance explained & 3.772 & 2.583 & 2.026 & 1.560 \\
\hline
\end{tabular}

\subsection{Reliability}

To evaluate the measures of the constructs in the study a reliability test analysis as performed. This was estimated by the Cronbach Alpha value and composite reliability. The composite reliability was estimated using the square of the summation of the factor loadings)/ \{(square of the summation of the factor loadings) + (summation of error variables) $\}$.

The interpretation of the resultant coefficient is similar to that of Cronbach's alpha, except that it takes into account the actual factor loadings rather than assuming that each item is equally weighted in the composite load determination.

The result in Table 6 showed the composite reliability of the main constructs in the study were above .70 and the Cronbach Alpha value all above .70 which met the recommendation by Nunnally (1978) except for the constructs, severity of patient illness, patient cooperation and provider motivation and satisfaction which were dropped from further analysis of the study. 


\section{Macrothink}

Table 3. Correlation among variables (total sample)

\begin{tabular}{|c|c|c|c|c|c|c|c|c|c|c|c|c|c|c|c|c|c|}
\hline Variables & $\mathbf{M}$ & SD & $\mathbf{S}$ & $\mathbf{K}$ & 1 & 2 & 3 & 4 & 5 & 6 & 7 & 8 & 9 & 10 & 11 & 12 & 13 \\
\hline 1. Age & -- & -- & -- & -- & --- & & & & & & & & & & & & \\
\hline $\begin{array}{l}\text { 2. Type of } \\
\text { healthcare }\end{array}$ & -- & -- & -- & -- & -.036 & --- & & & & & & & & & & & \\
\hline $\begin{array}{l}\text { 3. Visiting Health } \\
\text { Facility }\end{array}$ & -- & -- & -- & -- & .015 & $-.104^{*}$ & ----- & & & & & & & & & & \\
\hline $\begin{array}{ll}\text { 4. } & \text { Patient } \\
& \text { satisfaction }\end{array}$ & 4.24 & 622 & -.669 & -.489 & $.148^{* *}$ & .033 & $.159^{* *}$ & * 0.780 & & & & & & & & & \\
\hline $\begin{array}{ll}\text { 5. } & \text { Technical } \\
& \text { knowledge }\end{array}$ & 3.76 & .886 & $-.250-$ & -1.074 & 4.046 & $-.194^{* *}$ & $.157^{* *}$ & $* 034$ & 0.700 & & & & & & & & \\
\hline $\begin{array}{ll}\text { 6. } & \text { Provider } \\
& \text { responsiveness }\end{array}$ & 3.71. & .911 & -.583 & -.609 & .084 & $-.130^{* *}$ & $.165^{* *}$ & .000 & $.306^{* *}$ & 0.752 & & & & & & & \\
\hline 7. Provider facilities & s 3.64 . & .942 & -.547 & -.396 & .081 & $-.214^{* *}$ & $.183^{* *}$ & $* 067$ & $.419^{* *}$ & $* 382^{* *}$ & 0.718 & & & & & & \\
\hline $\begin{array}{l}\text { 8. Cost of } \\
\text { healthcare }\end{array}$ & 3.91. & .782 & $-.227-$ & -1.038 & 8-.002 & -.076 & .049 & $.176^{* *}$ & .042 & -.021 & .005 & 0.770 & & & & & \\
\hline $\begin{array}{l}\text { 9. Resources and } \\
\text { facilities }\end{array}$ & 3.93. & .729 & -.336 & -.682 & -.051 & -.060 & .061 & $.133^{* *}$ & .084 & -.069 & .001 & $.421^{* *}$ & 0.778 & & & & \\
\hline 10. Provider empathy & $y 3.74$. & .994 & -.563 & -.463 & -.064 & -.032 & $.142^{* *}$ & *.059 & $-.106^{*}$ & ${ }^{*}-.183^{* *}$ & $*-.208^{* *}$ & $.361^{* *}$. & $.305^{* * *}$ & 0.808 & & & \\
\hline 11. Collaboration & 3.85 & .761 & -.333 & -.841 & $-.128^{* *}$ & *.029. & $.136^{* *}$ & *089 & -.076 & $-.228^{* *}$ & $*-.202^{* *}$ & $.296^{* *}$ & $263^{* *}$. & $.280^{* *} \mathbf{0}$ & 0.802 & & \\
\hline $\begin{array}{l}\text { 12. Effective } \\
\text { leadership }\end{array}$ & 3.71. & .832 & -.424 & -.430 & .057 & -.022 & .060 & -.032 & -.046 & -.061 & -.083 & .041 & -.004 & $.331^{* *} .2$ & $270^{* *} \mathbf{0}$ & 0.700 . & \\
\hline 13. Service quality & 3.99. & .457 & -.428 & -.100 & .094 & $-.144^{* *}$ & $.318^{* *}$ & $.269^{* *}$ & $377^{* *}$ & *.294** & $.319^{* *}$ & $.192^{* *}$ & $199^{* *}$. & $.143^{* *} .1$ & $133^{* *} .1$ & $105^{*} \mathbf{0}$ & .710 \\
\hline${ }^{+} p<.10,{ }^{*} p<.05,{ }^{* *} p$ & $0<.0$ & $1,{ }^{* *}$ & $p<$ & .001 & & & & & & & & & & & & & \\
\hline M= Mean & & & & & & & & & & & & & & & & & \\
\hline $\mathrm{SD}=$ Standard deviati & & & & & & & & & & & & & & & & & \\
\hline $\mathrm{S}=$ Skewness & & & & & & & & & & & & & & & & & \\
\hline $\mathrm{K}=$ Kurtosis & & & & & & & & & & & & & & & & & \\
\hline
\end{tabular}

\subsection{Measures and Validation}

Measures development of the study began with hired field interviewers and pretests of the instrument among several healthcare facility users were done. These efforts helped develop and refine the measurement scales and the general survey design. Subsequently, details of the measures were provided and was used to assess the key constructs of the study as well as the control variables. The correlations, reliability indexes, and descriptive statistics of these constructs and control variables were also discussed. Table 4 shows details of the measures used in the study. 
Table 4. Factor loadings and reliability

\begin{tabular}{c}
\hline Construct \\
Technical \\
Knowledge \\
$\alpha=.795$ \\
CR $=0.75$ \\
AVE $=0.50$ \\
\\
Provider \\
responsiveness \\
$\alpha=.832$ \\
CR $=0.89$ \\
AVE $=0.57$ \\
\\
Provider facilities \\
$\alpha=.700$ \\
CR $=0.76$ \\
AVE $=0.56$ \\
CR $=0.44$ \\
SVE $=0.59$ \\
illness \\
$\alpha=.329$ \\
pevatient \\
c \\
\\
\end{tabular}

Patient cooperation ${ }^{c}$

$$
\begin{gathered}
\alpha=.345 \\
\mathrm{CR}=0.82 \\
\mathrm{AVE}=0.60 \\
\text { Provider } \\
\text { motivation } \\
\alpha=0.60 \\
\mathrm{CR}=0.76 \\
\mathrm{AVE}=0.39
\end{gathered}
$$

To what extent to you disagree or agree to the following statement relating to services provided by your healthcare facility

1. My doctor listens carefully to symptoms and signs before giving treatment

2. My doctor frequently checks my medical records
3. My doctor usually asks questions relating to the when, what, how and time of any sickness

4. My doctor considers my medical history before prescribing a drug

To what extent to you disagree or agree to the following statement relating to services provided by your healthcare facility

1. Caregivers in my hospital are friendly

2. My doctor maintains a professional rapport with me

3. Hospital officials respect my privacy

4. My doctor spends enough time with me

5. My doctor always tries to keep me from worrying

6. I get commitment relationship from hospital staff

To what extent to you disagree or agree to the following statement relating to services provided by your healthcare facility

1. The infrastructure used in my hospital is up to standard

2. I am assured of good satisfactory service from the existing facilities

3. There is adequate space to allow patients to wait and relax till his/her $\quad .586$ time to be served or attended to

To what extent to you disagree or agree to the following statement relating to services provided by your healthcare facility

1. My doctor is able to treat all my sickness

2. The hospital accommodates all types of illnesses $\quad .705$

3. It is easy to book appointment with a doctor on chronic ailment $\quad .668$

4. Inpatients ailments receive special caregivers

To what extent to you disagree or agree to the following statement relating to services provided by your healthcare facility

1. I reveal the truth about my sickness to my doctor

2. I follow medical directions of my doctor

To what extent to you disagree or agree to the following statement relating to services provided by your healthcare facility

1. Caregivers are motivated in this facility .683

2. My doctor expresses satisfaction in working in the hospital $\quad .556$

3. The doctors often get promoted in this hospital 689

4. The organisational policy in this hospital is fair .594

$$
\begin{gathered}
\begin{array}{c}
\text { Provider } \\
\text { competency }
\end{array} \\
\alpha=.822 \\
\mathrm{CR}=0.820 \\
\mathrm{AVE}=0.60
\end{gathered}
$$

Provider empathy

$$
\alpha=.905
$$

$\mathrm{CR}=0.84$

$\mathrm{AVE}=0.65$
To what extent to you disagree or agree to the following statement relating to services provided by your healthcare facility

1. The hospital gives staffs training on new methods of treatment $\quad .751$

2. The hospital operates within international caring standards $\quad .812$

3. All referrals in the hospital leads to my doctor

To what extent to you disagree or agree to the following statement relating to services provided by your healthcare facility

1. Knowledge and information are shared between patients and care givers

2. There is transparency of care between caregivers and the patient

3. There is good rapport between patients and providers 
4. My doctor treats me with respect

5. All medications given to me by my doctors gives a positive results

Cost of healthcare

$\alpha=.820$

$\mathrm{CR}=0.88$

$\mathrm{AVE}=0.59$

\section{Resources and facilities \\ $\alpha=.717$ \\ $\mathrm{CR}=0.93$ \\ $\mathrm{AVE}=0.61$}

To what extent to you disagree or agree to the following statement relating to services provided by your healthcare facility

1. The hospital has an effective referral system in place

2. I am registered on the NHIS which my hospital accepts

3. The hospital has a good support system for patients

.540

4. There are enough medical consultant/specialist in my hospital

5. Consultation fees are non-discriminatory on type of illness

To what extent to you disagree or agree to the following statement relating to services provided by your healthcare facility

1. The hospital has the required facility to deliver quality service

2. The hospital uses advanced technology in giving healthcare

3. The sight of the hospital environment can make me get well

4. The hospital has in place an effective information system

5. The hospital has in place a state of the art facilities

Effective leadership

$$
\alpha=.609
$$

$\mathrm{CR}=0.77$

$\mathrm{AVE}=0.50$

Collaboration

$$
\begin{gathered}
\alpha=.70 \\
\mathrm{CR}=0.74 \\
\mathrm{AVE}=0.64
\end{gathered}
$$

Patient satisfaction

$$
\begin{gathered}
\alpha=.762 \\
\mathrm{CR}=0.86 \\
\mathrm{AVE}=0.61
\end{gathered}
$$

To what extent to you disagree or agree to the following statement relating to services provided by your healthcare facility

1. The selection of hospital managers is based on objective criteria

2. The hospital has a way of receiving feedback from patients

3. There is bureaucracy in my hospital

To what extent to you disagree or agree to the following statement relating to services provided by your healthcare facility

1. The hospital I use has good reputation

2. There is effective support service in my hospital

3. Doctors and co-workers work in harmony professional in delivering healthcare

To what extent to you disagree or agree to the following statement relating to services provided by your healthcare facility

1. All things considered, the medical care you receive is excellent

Note: $\mathrm{FL}=$ Factor loadings. $\mathrm{CR}=$ Composite reliability, AVE = Average Variance Extracted

${ }^{a}$ Only two items were used to measure this construct which is seen as major limitation for this study

${ }^{\mathrm{c}}$ Construct was dropped from further analysis of the study due to low reliability or validity

All items were measured on five-point scales anchored by "strongly disagree" and "strongly agree". 
Table 4 contd. Factor loadings and reliability

\begin{tabular}{|c|c|c|}
\hline Construct & Item description & FL \\
\hline \multicolumn{3}{|l|}{ Service quality } \\
\hline Reliability $^{\mathbf{b}}$ & $\begin{array}{l}\text { To what extent to you disagree or agree to the following statement } \\
\text { relating to services provided by your healthcare facility }\end{array}$ & 0.677 \\
\hline$\alpha=.833$ & 1. Carrying out of the services right at the first time & .531 \\
\hline $\mathrm{CR}=0.88$ & 2. Providing services at appointed time & .904 \\
\hline $\mathrm{AVE}=0.60$ & 3. Error-free and fast retrieval of documents & .706 \\
\hline & 4. Telling when services will be performed & .767 \\
\hline Responsiveness ${ }^{\mathrm{b}}$ & $\begin{array}{l}\text { To what extent to you disagree or agree to the following statement } \\
\text { relating to services provided by your healthcare facility }\end{array}$ & 0.720 \\
\hline$\alpha=.708$ & 1. Attending of personnel whenever called & .819 \\
\hline $\begin{array}{c}\mathrm{CR}=0.81 \\
\mathrm{AVE}=0.50\end{array}$ & 2. Instilling confidence in patients & 675 \\
\hline Empathy & $\begin{array}{l}\text { To what extent to you disagree or agree to the following statement } \\
\text { relating to services provided by your healthcare facility }\end{array}$ & 0.73 \\
\hline$\alpha=.805$ & 1. Polite and friendly dealing of personnel with patients & .658 \\
\hline $\mathrm{CR}=0.88$ & 2. Knowledgeable personnel to answer patient questions & .807 \\
\hline $\mathrm{AVE}=0.72$ & 3. Individual attention to patients & .811 \\
\hline Tangibility $^{\mathbf{b}}$ & $\begin{array}{l}\text { To what extent to you disagree or agree to the following statement } \\
\text { relating to services provided by your healthcare facility }\end{array}$ & 0.710 \\
\hline$\alpha=.774$ & 1. Clean and comfortable environment of the hospital & 668 \\
\hline $\mathrm{CR}=0.86$ & 2. Modern and up to date equipment & .897 \\
\hline $\mathrm{AVE}=0.60$ & 3. Visual appeal of physical facilities & .737 \\
\hline
\end{tabular}

Note: $\mathrm{FL}=$ Factor loadings. $\mathrm{CR}=$ Composite reliability, AVE = Average Variance Extracted

${ }^{\text {b}}$ These constructs were composited to represent the main service quality construct (Aiken \& West, 1991)

All items were measured on five-point scales anchored by "strongly disagree" and "strongly agree".

Service quality. Service quality was defined as the extent to which the provided service meets the aspirations, needs or expectations of the customer (Asubonteng, McCleary, \& Swan, 1996). The items for service quality construct constituted tangibility, reliability, responsiveness, assurance, and empathy. Respondents were instructed to show the extent to which they agreed or disagreed with statements of service quality on a 5-point Likert scale, 1 indicating strongly disagree and 5, indicating, strongly agree. This scale was adapted from Parasuraman, Zeithaml and Berry (1988) study. Tangibility related to the appeal of facilities, equipment and material used by a service firm as well as to the appearance of service employees (Gronroos, 2006). Reliability focused on the service firm provides its customers with accurate service the first time without making any mistakes and delivers what it has promised to do by the time that has been agreed upon (Gronroos, 2006). Responsiveness referred to the employees of a service firm are willing to help customers and respond to their requests a well as to inform customers when service will be provided, and then give prompt service (Gronroos, 2006). Assurance described employees' behavior to give customers confidence in the firm. Empathy relate to how firm understands customers' problems and performs in their best interests as well as giving customers individual personal attention and having convenient operating hour (Gronroos, 2006). A second-order factor structure was examined by conducting a one-factor CFA on the summed scores of the respective four first-order constructs. The model fit was good lending support to the second-order factor conceptualization for service quality $\left(\chi^{2}=142.845\right.$, degrees of freedom [d.f.] $=80$; 
goodness-of-fit index $[\mathrm{GFI}]=.960$; adjusted goodness-of-fit index $[\mathrm{AGFI}]=.940 ; \mathrm{CFI}=.972$; $\mathrm{TLI}=.963 ; \mathrm{RMSEA}=.042 ; \mathrm{NFI}=.936)$

Control factors. To ensure the age of the respondent, facility type, years of using facility and use of insurance does not bias the results of the impact of organisational, environmental, provider related factors on service quality and performance they were controlled. Also, patient satisfaction was also controlled for.

\subsection{Results}

A multiple regression analysis was performed to test hypotheses developed for the study. The data was analyzed using the enter method procedure. To determine the impact of the independent variables on the service quality, organisational, patient related, provider related and environmental factors were regressed on the dependent variable, service quality.

\section{Factors affecting service quality}

Model A in Table 5 shows that the control variable explained $16.8 \%$ of the variance in service quality. The introduction of the independent variables in the next model together with control variables in Model $\mathrm{B}$, explained 30.5\% $\left(\Delta R^{2}=.137, \Delta F=11.123, p<.000\right)$ of the variance in service quality.

Table 5. Regression analysis of organisational, patient related, provider related and environmental factors on service quality

\begin{tabular}{|c|c|c|}
\hline & \multicolumn{2}{|c|}{ Total sample } \\
\hline & \multicolumn{2}{|c|}{ Model A } \\
\hline & $\beta$ (t-values) & $\beta$ (t-values) \\
\hline \multicolumn{3}{|l|}{ Control variables } \\
\hline Age & $-.051(-1.123)$ & $-.018(-.419)$ \\
\hline Type of healthcare & $-.122(-2.661)^{* * *}$ & $-.052(-1.193)$ \\
\hline Visiting healthcare (yrs) & $.267(5.755)^{* * * *}$ & $.196(4.433)^{* * *}$ \\
\hline Customer satisfaction & $.231(4.996)^{* * * *}$ & $.206(4.713)^{* * *}$ \\
\hline \multicolumn{3}{|l|}{ Independent variables } \\
\hline \multicolumn{3}{|l|}{ Organisational factors } \\
\hline H1: Technical knowledge & & $.268(4.351)^{* * *}$ \\
\hline $\mathrm{H} 2$ : Provider responsiveness & & $.120(1.732)^{+}$ \\
\hline H3: Provider facilities & & $.003(.041)$ \\
\hline \multicolumn{3}{|l|}{ Provider-related factors } \\
\hline H8: Provider competency & & $.080(1.487)$ \\
\hline \multicolumn{3}{|l|}{ Environmental factors } \\
\hline H9: Cost of health care & & $-.090(-1.938)^{*}$ \\
\hline H10: Effective leadership & & $.077(1.706)^{+}$ \\
\hline H11: Collaboration & & $.145(2.852)^{* * *}$ \\
\hline $\mathrm{R}^{2}$ & .168 & .305 \\
\hline F value & $20.206^{* * * *}$ & $15.725^{* * *}$ \\
\hline$\Delta \mathrm{R}^{2}$ & .168 & .137 \\
\hline$\Delta \mathrm{F}$ value & $20.206^{* * * *}$ & $11.123^{* * *}$ \\
\hline Degrees of freedom & $4 / 401$ & $7 / 394$ \\
\hline
\end{tabular}


${ }^{+} p<.10,{ }^{*} p<.05,{ }^{* *} p<.01,{ }^{* * *} p<.001$ (one-tailed test). Note: Standardized regression coefficients were reported with t-values for each effect in parentheses.

\subsection{Discussions}

From the regression analysis, hypothesis relationships with $\mathrm{p}$-value $>0.10$ were rejected whiles those with $\mathrm{p}$-values $<0.10$ were accepted and discussed. The first hypothesis that, there was a positive relationship between technical knowledge of healthcare and perceived service quality was supported. From the model, we could deduce that, if technical knowledge of healthcare personnel increase by a unit, perceived service quality of patients increases by 26.8 percent. This results in line with the revelation of Donabedian (1986) who affirmed that the technical competence of healthcare givers is the most important in the service quality process of patients. Gronroos (1983) also assert that, patients' perceptions of the service quality depend on the service they receive from caregivers and this is also supported by other researchers (e.g. Maddern, Maull, Smart \& Baker, 2007) who were also of the view that the technical knowledge of the healthcare facilities translates into higher patients' perceived quality. In the hospital setting, when the care givers are experienced and knowledgeable in their field of expertise, patient feel safe and confident in dealing with the personnel involved. When patients do not trust the technical knowledge of healthcare providers, they will not be willing to receive healthcare service.

The disconfirmation theory stresses that, when patients trust the technical knowledge of their service providers, then it leads to higher perception of service quality leading to their overall satisfaction. Technical competence on the part of service providers makes patients makes patients comfortable because they believe healthcare gives possess the required competence to offer them medical care. Since service is inseparable, the contribution of the caregivers or doctors relating to their technical knowledge, responsiveness, and competency to a large extent could impact on the perceive service quality of the patients. From the result obtained, it is therefore needful for caregivers to possess the required competencies, traits, skills and knowledge in order to deliver optimal level of service to patients. Litchfield et al (2002) assert that when there are higher competencies like permanent learning, communication and critical thinking, it equips the providers to provide quality services which leads to patient satisfaction and perceived service quality because the expectations of patients are met

Secondly, there was also support for the positive relationship between provider responsiveness and perceived service quality of healthcare. According to the model, a unit increase in provider responsiveness will increase patients' perceived service quality by 12 percent. This shows how significant provider responsiveness is, to patient service quality. Murray and Frenk (2000) in their study identified respect for patients and patient orientation as important dimensions of provider responsiveness which can lead to higher service quality. Using the disconfirmation theory, they show that when healthcare givers become sensitive to the plight of the patients, there is positive perception of the patients towards caregivers. Provider responsiveness could impact on perceived quality of the patient when there is respect for their basic human right and respect for the patients' autonomy. A higher positive perception of hospital quality is achieved when doctors put themselves in the shoes of the patients, feel 
their patients and be in the position to offer prompt services to them. This result is consistent with the research conducted by Charles et al (1997), Tucker and Adams (2001) and Murray and Frenk (2000) who also identified provider responsiveness as importance element in achieving higher perceived service quality of patients. For example, Taylor and Cronin (1994) was of the view that perceptions of patients concerning how hospital staffs relates to them is an important indicator of perceived quality as their expectations are met. They recommend that for service quality to be high, there is the need to develop quality measures such as respect, expert judgement and positive demeanor of healthcare givers.

Also, there was a negative relationship between cost of healthcare and perceived service quality of patients. From the regression analysis, we could infer that, if cost of healthcare increases by a unit, perceived service quality of patients will reduce by 9 percent. This attest to the fact that there is a negative relationship between cost of healthcare and patients perceived service quality. The cost of assessing healthcare is an important predictor of quality especially to low-income earners. When the hospital also accepts health insurance cards, it makes them easy to assess healthcare without any worry. When there are interrelations in the health system, there is higher patient satisfaction. When the cost of providing healthcare is high, patient might resort to some other means of taking care of themselves, thereby having a negative perception about the service provided.

When the cost of receiving healthcare is affordable, patients are able to visit hospital facilities because they are in the position to pay for the service. Healthcare should be affordable for all to assess and this will lead to higher satisfaction which invariably translates to higher perceived quality in the perspective of the patients. In general, although patients want to be treated, people who are low-income earners or do not earn enough will normally go to hospitals and clinics that they can afford. People look at their financial standing before deciding on the type of hospital to go for medical care. When the cost of healthcare is expensive in Facility 'A', they find alternative medical care in Facility ' $B$ '. It is therefore not surprising that, there was a negative relationship between cost of healthcare and perceived service quality.

There was also support for the positive relationship between effective leadership and perceived service quality of healthcare. The regression results suggested a direct relationship between effective leadership and perceived service quality of respondents. This result is consistent with some prior empirical research (e.g. Mosadeghrad \& Hossein, 2006; Benzer et al., 2012; Al-Mailam, 2004) which suggested that most problems faced by healthcare facilities are due to bad leadership. According to Mosadeghrad and Hossein (2006), poor leadership reduces effectiveness, efficiency and increases cost and ultimately resulting in dissatisfaction among staffs and lowering patients' satisfaction, because caregivers do not give their best in the delivery of service. When there is effective leadership, it reduces conflict among staffs and their departments and this helps in advancing the performance of the facility (Benzer et al., 2012).

There was also support for the positive relationship between collaboration between healthcare providers and perceived service quality of healthcare. When there is a unit increase in 
collaboration between healthcare facilities, perceived service quality of patients' increases by 14.5 percent. This suggest information and knowledge sharing between healthcare facilities is importance to enhance service quality. The research conducted by Mosadeghrad (2014) support this results. It is important to state that, knowledge does not reside in the mind of a person and therefore there is collaboration relating to new methods, new discoveries, new sicknesses and diseases, then it helps service providers to understand and know how to treat such ailments. When there is collaboration, experiences are shared between health professional and with this caregiver provide standard forms of treatment based on best practices elsewhere.

Similarly, when there is good communication between caregivers of different facilities, they are able to share information and knowledge on particular illness, and with this, they are in the position to better provide the needed medication and treatment of their patients. Also, when there is a good referral system in place and collaboration between various healthcare workers and facilities, patients are easily referred to place where they could receive specialized care. Hospitals which do not collaborate with other facilities, then to provider restricted service even if they are not capable of providing the required service to a patient

\subsection{Implications for Management of Healthcare Facilities in Ghana}

The study recommends that stakeholders and management invest more into the training of hospital staffs in these critical areas of service delivery. This training could equip healthcare personnel like Doctors, Nurses, Administrators, Optometrists, Pharmacists the required competences to handle their patients who come to their healthcare facilities.

The study further recommends that, doctors should listen carefully to the symptoms and signs of patients before giving medication. It is also important for doctors to check the medical records and asking questions relating to the when, what, and time of the sickness of patients before giving medication.

It is important to also state that, caregivers should be responsiveness to the needs of their patients. There is the need for prompt medical and non-medical services for patients in the hospital. Healthcare personnel should be willing and able to help patients in their service delivery journal from walking to the hospital to register to seeing a doctor to be treated.

As the law of demand goes "The higher the price, the low the quantity demanded". It is therefore not surprising that, there was a significant and negative relationship between cost of healthcare and perceived service quality of patients. Due to this established relationship, hospital management should have an effective referral system and be able to accept the government national health insurance cards. Since, the national health insurance is affordable and most Ghanaians are able to do, both the private and public healthcare facilities should accept this card, to enable patients use their facilities to access healthcare. The hospitals should have a good support system for patients and also ensure that consultation fees are non-discriminatory on type of illness.

Another implication that can be drawn from this study is that, the selection of hospital managers in healthcare facilities should be based on objective criteria. The recruitment and 
selection of personnel especially in the public healthcare facilities, should be based on competences and not 'whom you know' at the top. Managers of healthcare facilities should be selected based on their managerial skills and not based on their political affiliations. In addition to this, the hospital should have a way of receiving feedback from patients and reduce the extent of bureaucracy.

Lastly, healthcare providers should be able to communicate with other professional in delivering healthcare. When there is collaboration between different hospitals, medical practitioners are able to learn from each other by way of new methods of treatment and other best practices used elsewhere. When there is no collaboration, there is no information sharing and therefore old methods and practices will be used. For example, in the treatment of malaria previously Chloroquine, but now we used Artesunate Amodiaquine and Atemether Lumenfantrine due to the non-use of mono therapy by World Health Organisation. They now recommend the use of dual therapy for enhancing the treatment of malaria. This is possible through collaboration and information sharing. In the same hospital too, practitioners should share information among units and department to be abreast with happenings and situations of patients in the hospital.

\subsection{Limitations of the Study}

There is the need to recognize some theoretical limitations. Firstly, severity of illness which was meant to test hypothesis 4 was dropped in the final analysis due to low reliability of 0.329. Severity of illness was an important variable but because it did not satisfy the requirement of the analysis it was taken out of the research. Patient cooperation and provider motivation and satisfaction also had low reliabilities and low Average Variance Explained respectively and therefore they were also dropped. Other future researchers should take a second look at the constructs and find other scales to measure them.

\subsection{Implication for Future Research}

In suggesting to future researcher, the two models, private and public healthcare facilities are perceived to be significantly different. The variables which lent support to public was different from that of the private. Future research should therefore expand the scope of this research by focusing on each one of them and draw conclusions based on their respective findings.

This research studied four major factors namely, organisational factors, patient related factor, provider related factors and environmental factors. However, it is recommended that future research should concentrate on each of these factors and their dimensions to get a better insight into how each one of them could impact on patents' perceived service quality.

Though there was a significant and positive relationship between technical knowledge, provider responsiveness, cost of healthcare, effective leadership, collaboration and perceived service quality of patients, there are also indications that suggest that such influences are contingent on internal and external conditions. These internal and external conditions require further interrogation by future researchers. In effect, future researchers should be concerned about establishing the internal and external moderating conditions under which provider 
responsiveness, cost of healthcare, effective leadership and collaboration will have a strong impact or reduce their impact on perceived service quality of patients.

The service quality construct should be re-looked again. This is because the researcher adopted the validated scales of Parasuraman, Zeithaml and Berry (1988) which although had been tested already, is not contextual to emerging or developing economies considering the differences that exist in health sectors across the various countries. Future researchers could therefore consider developing a contextual scale for measuring service quality for developing and emerging economies. This will help to give a clearer indication of the case of Ghana and respondents will understand and appreciate the questions posed to them. This scale will also help future researcher to better compare service quality of patients in private and public healthcare facilities.

\subsection{Conclusions}

The study was aimed at finding out the factors affecting perceived service quality among patients of private healthcare facilities in Ghana. It was revealed that, there was a positive and significant relationship between technical knowledge and service quality. It was also revealed that, provider responsiveness of healthcare was similarly significantly and positively related to service quality. Under environmental factors, there was a negative and significant relationship between cost of healthcare and service quality. Similarly, there was a positive relationship between effective leadership and service quality and also collaboration of healthcare institutions and service quality also had a significant relationship.

\section{Acknowledgement and Sponsoring Information}

The authors declare no sponsors of the research. There is also no conflict-of-interest issues to declare.

\section{References}

Amanfi, J. (2012). Service Quality and Customer Satisfaction in Public Sector Organizations. a Case Study of the Commission of Human Right and Administrative Justice (Doctoral dissertation, Institute of Distance Learning, Kwame Nkrumah University of Science and Technology).

Andaleeb, S. S. (2001). Service quality perceptions and patient satisfaction: a study of hospitals in a developing country. Social Science \& Medicine, 52(9), 1359-1370.

https://doi.org/10.1016/S0277-9536(00)00235-5

Benzer, J. K., Beehler, S., Miller, C., Burgess, J. F., Sullivan, J. L., Mohr, D. C., ... \& Cramer, I. E. (2012). Grounded theory of barriers and facilitators to mandated implementation of mental health care in the primary care setting. Depression research and treatment, 2012.

https://doi.org/10.1155/2012/597157

Bryman, A. (2004). Qualitative research on leadership: A critical but appreciative review. The leadership quarterly, 15(6), 729-769.

https://doi.org/10.1016/j.leaqua.2004.09.007 
Bryman, A. (2004). Triangulation and measurement. Retrieved from Department of Social Sciences, Loughborough University, Loughborough, Leicestershire: www. referenceworld. $\mathrm{com} /$ sage/socialscience/triangulation. pdf.

Carey, K. B., Norris, A. L., Durney, S. E., Shepardson, R. L., \& Carey, M. P. (2018). Mental health consequences of sexual assault among first-year college women. Journal of American college health, 66(6), 480-486. https://doi.org/10.1080/07448481.2018.1431915

Charles, C., Gafni, A., \& Whelan, T. (1997). Shared decision-making in the medical encounter: what does it mean?(or it takes at least two to tango). Social science \& medicine, 44(5), 681-692. https://doi.org/10.1016/S0277-9536(96)00221-3

Cronin Jr, J. J., \& Taylor, S. A. (1994). SERVPERF versus SERVQUAL: reconciling performance-based and perceptions-minus-expectations measurement of service quality. Journal of marketing, 58(1), 125-131. https://doi.org/10.1177/002224299405800110

Donabedian, A. (1980). Exploratings in quality assessment and monitoring definition of quality and approaches to its assessment. Ann Arbor

Eiriz, V., \& Figueiredo, J. A. (2005). Quality evaluation in health care services based on customer-provider relationships. International journal of health care quality assurance https://doi.org/10.1108/09526860510619408

García, P. J. (2019). Corruption in global health: the open secret. The Lancet, 394(10214), 2119-2124. https://doi.org/10.1016/S0140-6736(19)32527-9

Ghiasipour, M., Mosadeghrad, A. M., Arab, M., \& Jaafaripooyan, E. (2017). Leadership challenges in health care organizations: The case of Iranian hospitals. Medical journal of the Islamic Republic of Iran, 31, 96. https://doi.org/10.14196/mjiri.31.96

Gronroos, C. (1990). Relationship approach to marketing in service contexts: The marketing and organizational behavior interface. Journal of business research, 20(1), 3-11.

https://doi.org/10.1016/0148-2963(90)90037-E

Hair, J. F., Black, W. C., Babin, B. J., \& Anderson, R. E. (2010). Canonical correlation: A supplement to multivariate data analysis. Multivariate data analysis: a global perspective. 7 th edn. Pearson Prentice Hall Publishing, Upper Saddle River.

Irfan, S. M., \& Ijaz, A. (2011). Comparison of service quality between private and public hospitals: Empirical evidences from Pakistan. Journal of Quality and Technology Management, $7(1), 1-22$.

Jackson, J. L., Chamberlin, J., \& Kroenke, K. (2001). Predictors of patient satisfaction. Social science \& medicine, 52(4), 609-620. https://doi.org/10.1016/S0277-9536(00)00164-7

Jonsdottir, H., Litchfield, M., \& Pharris, M. D. (2004). The relational core of nursing practice as partnership. Journal of advanced nursing, 47(3), 241-248.

https://doi.org/10.1111/j.1365-2648.2004.03088_1.x

Jun, M., Peterson, R. T., \& Zsidisin, G. A. (1998). The identification and measurement of 
quality dimensions in health care: focus group interview results. Health care management review, 23(4), 81-96. https://doi.org/10.1097/00004010-199810000-00007

Keenan, K. F., Van Teijlingen, E., \& Pitchforth, E. (2005). The analysis of qualitative research data in family planning and reproductive health care. BMJ Sexual \& Reproductive Health, 31(1), 40-43. https://doi.org/10.1783/0000000052972825

Khalifa, M., \& Liu, V. (2003). Determinants of successful knowledge management programs. Electronic Journal on Knowledge Management, 1(2), 103-112.

Maddern, H., Maull, R., Smart, A., \& Baker, P. (2007). Customer satisfaction and service quality in UK financial services. International Journal of Operations \& Production Management, 27(9), 999. https://doi.org/10.1108/01443570710775838

Mathauer, I., \& Imhoff, I. (2006). Health worker motivation in Africa: the role of non-financial incentives and human resource management tools. Human resources for health, 4(1), 1-17.

https://doi.org/10.1186/1478-4491-4-24

Matsea, T., Ryke, E., \& Weyers, M. (2018). Assessing mental health services in a rural setting: Service providers' perspective. International Journal of Mental Health, 47(1), 26-49. https://doi.org/10.1080/00207411.2017.1377805

McKinney, V., Yoon, K., \& Zahedi, F. M. (2002). The measurement of web-customer satisfaction: An expectation and disconfirmation approach. Information systems research, 13(3), 296-315. https://doi.org/10.1287/isre.13.3.296.76

Medina-Perucha, L., Yousaf, O., Hunter, M. S., \& Grunfeld, E. A. (2017). Barriers to medical help-seeking among older men with prostate cancer. Journal of psychosocial oncology, 35(5), 531-543. https://doi.org/10.1080/07347332.2017.1312661

Merriam, S. B. (1998). Qualitative Research and Case Study Applications in Education. Revised and Expanded from" Case Study Research in Education. ". Jossey-Bass Publishers, 350 Sansome St, San Francisco, CA 94104.

Mosadeghrad, A. M. (2014). Factors influencing healthcare service quality. International journal of health policy and management, 3(2), 77. https://doi.org/10.15171/ijhpm.2014.65

Mosadeghrad, A. M., \& Abbasi, M. A. H. D. I. (2018). Performance of the Nursing Managers in the Hospitals in Sari, Iran. Iran Journal of Nursing, 31(115), 62-74.

https://doi.org/10.29252/ijn.31.115.62

Murray, C. J., \& Frenk, J. (2000). A framework for assessing the performance of health systems. Bulletin of the world Health Organization, 78, 717-731.

Nunnally, J. C. (1978). Psychometric theory McGraw-Hill book company. INC New York.

Ojwang, B. O., Ogutu, E. A., \& Matu, P. M. (2010). Nurses' impoliteness as an impediment to patients' rights in selected Kenyan hospitals. Health \& Hum. Rts., 12, 101.

Owusu-Frimpong, N., Nwankwo, S., \& Dason, B. (2010). Measuring service quality and 
patient satisfaction with access to public and private healthcare delivery. International Journal of Public Sector Management, 23(3), 203-220. https://doi.org/10.1108/09513551011032455

Pakdil, F., \& Harwood, T. N. (2005). Patient satisfaction in a preoperative assessment clinic: an analysis using SERVQUAL dimensions. Total Quality Management \& Business Excellence, 16(1), 15-30. https://doi.org/10.1080/1478336042000255622

Protzman, C., Mayzell, G., \& Kerpchar, J. (2018). Appendix 1. Lean Practitioner Quiz. In Leveraging Lean in Healthcare (pp. 373-374). Productivity Press.

https://doi.org/10.1201/b10406-34

Salisbury, C., Wallace, M., \& Montgomery, A. A. (2010). Patients' experience and satisfaction in primary care: secondary analysis using multilevel modelling. Bmj, 341.

https://doi.org/10.1136/bmj.c5004

Shafiq, M., Naeem, M. A., Munawar, Z., \& Fatima, I. (2017). Service quality assessment of hospitals in Asian context: An empirical evidence from Pakistan. INQUIRY: The Journal of Health Care Organization, Provision, and Financing, 54, 0046958017714664.

https://doi.org/10.1177/0046958017714664

Spreng, R. A., \& Mackoy, R. D. (1996). An empirical examination of a model of perceived service quality and satisfaction. Journal of retailing, 72(2), 201-214.

https://doi.org/10.1016/S0022-4359(96)90014-7

Tucker III, J. L., \& Adams, S. R. (2001). Incorporating patients' assessments of satisfaction and quality: An integrative model of patients' evaluations of their care. Journal of Service Theory and Practice, 11(4), 272 https://doi.org/10.1108/EUM0000000005611

Werner, R. M., \& Chang, V. W. (2008). The relationship between measured performance and satisfaction with care among clinically complex patients. Journal of general internal medicine, 23(11), 1729-1735. https://doi.org/10.1007/s11606-008-0734-6

Zeithaml, V. A., Berry, L. L., \& Parasuraman, A. (1988). Communication and control processes in the delivery of service quality. Journal of marketing, 52(2), 35-48.

https://doi.org/10.1177/002224298805200203

\section{Copyright Disclaimer}

Copyright for this article is retained by the author(s), with first publication rights granted to the journal.

This is an open-access article distributed under the terms and conditions of the Creative Commons Attribution license (http://creativecommons.org/licenses/by/4.0/). 